\title{
Traçando um perfil para o professor de Física da Educação Básica: o que preconiza a legislação brasileira?
}

\author{
Lisiane Araujo Pinheiro*, Neusa Massoni**
}

\section{Resumo}

O presente texto compõe uma pesquisa mais abrangente que, no âmbito de uma tese de doutorado, pretende refletir a formação inicial de professores de Física no Brasil. Este artigo discute o perfil do educador de Física a partir de uma análise dos documentos legais que regem o Ensino Médio e o Ensino Superior. A elaboração desse perfil foi dividida em duas etapas: a primeira apresenta o perfil do professor de Física esperado pelos documentos legais que regem o Ensino Médio, que é o maior espaço de atuação do licenciado em Física; a segunda mostra o perfil pretendido do licenciado em Física a partir dos documentos que orientam a Formação de Professores no Ensino Superior. Com a constituição desse perfil, promove-se sua articulação com referenciais teóricos e com a literatura sobre saberes docentes e, assim, pensa-se em investigações mais propositivas na tese. Contudo, entende-se que mostrar esses perfis pode contribuir com o debate vigente sobre a formação de professores em nosso país, especialmente dada a complexidade de saberes, capacidades, habilidades, valores e ações que se espera desse educador segundo os documentos oficiais.

Palavras-chave: Perfil do professor de Física. Formação inicial. Políticas públicas.

* Doutoranda no Programa de Pós-Graduação em Ensino de Física da Universidade Federal do Rio Grande do Sul. Brasil. E-mail: lisianearaujopinheiro@gmail.com

** Departamento de Física, Instituto de Física da Universidade Federal do Rio Grande do Sul. Brasil. E-mail: neusa.massoni@ufrgs.br

Recebido em: 26/04/2020 - Aceito em: 01/10/2020

https://doi.org/ 10.5335/rbecm.v4i1.10897

http://creativecommons.org/licenses/by-nc-nd/4.0 


\section{Introdução}

Os documentos oficiais brasileiros promoveram, nas últimas décadas, mudanças significativas no Ensino Médio, especialmente quando este passou a compor a Educação Básica em sua etapa final, na década de 1990. De um olhar propedêutico para o ensino (BRASIL, 1971), passou-se a focar uma formação para o trabalho e para a cidadania (BRASIL, 1996), com claros reflexos na sala de aula, de acordo com os documentos estruturantes do Ensino Médio.

Uma nova proposta de Ensino Médio foi continuamente sendo apresentada pelos documentos oficiais (BRASIL, 1996, 1998, 1999, 2002, 2006, 2010, 2012, 2016b, 2018). Caberiam, então, algumas perguntas: esses documentos foram amplamente divulgados e discutidos nas escolas e nos cursos de formação de professores? O professor foi ouvido na fase de elaboração dessas políticas públicas? O que esses documentos pretendiam dizer a seus interlocutores? A proposta do novo Ensino Médio veio acompanhado de condições para ser executada? Essas e muitas outras perguntas sobre a estruturação do Ensino Médio brasileiro são atuais e pertinentes.

Tentando estabelecer uma relação entre o que se espera do ensino de Física e a formação do docente de Física brasileiro, fizemos uma análise documental e uma comparação entre o que preconizam os documentos que legislam sobre o Ensino Médio e as Diretrizes Curriculares sobre a Formação de Professores (BRASIL, 2002) e as Diretrizes para a Formação de Profissionais do Magistério da Educação Básica (BRASIL, 2015). Com base nos conceitos e princípios mais presentes nos documentos do Ensino Médio, traçamos um perfil esperado do egresso da Licenciatura em Física e buscamos articular esse perfil com os conceitos emergentes da análise da legislação sobre a formação de professores visando perceber se esses dois blocos de políticas públicas estão articulados, se são coerentes entre si.

Aspectos metodológicos

O estudo aqui apresentado constitui uma pesquisa qualitativa do tipo estudo documental. Todos os achados emergiram da leitura de dois blocos de documentos, como já mencionado, e de procedimentos de análise da Teoria Fundamentada (STRAUSS, 1987). Por meio da microanálise de alguns documentos, identificamos um conjunto de conceitos que consideramos estruturantes para o Ensino Médio. A microanálise é uma técnica de análise linha por linha que busca por significados dos termos que se mostram mais presentes com o fim de identificar conceitos, cate- 
gorias. A partir da técnica do questionamento, refletimos sobre como esses conceitos eram apresentados nos demais documentos oficiais e como eles compõem um perfil esperado para o docente de Física em nível médio.

Na sequência, através da técnica da comparação, tal perfil foi comparado com o que emergiu da microanálise das Diretrizes Curriculares Nacionais para a Formação Inicial e Continuada de Profissionais do Magistério da Educação Básica (BRASIL, 2015) e das Diretrizes precedentes (BRASIL, 2002) em um processo de busca de propriedades e dimensões como é próprio de uma comparação teórica. Desse processo emergiram dois conjuntos de conceitos que expressamos como "aspectos psicológicos" e "aspectos profissionais" do perfil esperado e do perfil pretendido do professor de Física para o Ensino Médio no Brasil, que nos permitiram construir representações esquemáticas do tipo espinha de peixe (Figuras 1 e 2). Na sequência, detalhamos como essa construção foi ocorrendo ao longo da análise.

\section{Ensino Médio: uma análise dos documentos oficiais brasileiros e a busca de categorias que refletem o Ensino Médio esperado}

Inicialmente analisamos os seguintes documentos: Constituição Federal do Brasil (BRASIL, 1988); Lei de Diretrizes e Bases da Educação (BRASIL, 1996); Diretrizes Curriculares Nacionais para o Ensino Médio - DCNEM (BRASIL, 1998); Parâmetros Curriculares Nacionais - Ciências da Natureza, Matemática e suas Tecnologias (BRASIL, 1999); Orientações Educacionais Complementares aos Parâmetros Curriculares Nacionais PCN+ (BRASIL, 2002); Orientações Curriculares Para o Ensino Médio - OCEM (BRASIL, 2006); Diretrizes Curriculares Nacionais para o Ensino Médio (BRASIL, 2012); Plano Nacional de Educação (BRASIL, 2014); Base Nacional Comum Curricular para o Ensino Médio (BRASIL, 2018). Esses documentos compõem o Bloco 1, cuja análise objetivou identificar o ensino médio e o perfil esperado do professor de Física pela legislação. Destacamos que a Constituição e a LDB foram analisados nos dois blocos porque regem ambos os níveis do sistema educacional.

Fizemos, inicialmente, um escrutínio dos documentos oficiais que orientaram/ orientam a estruturação de um Ensino Médio no país nas últimas três décadas. Por meio da técnica da microanálise, identificamos alguns conceitos que atravessam os vários documentos oficiais, em função de sua importância, significado e 
repetitividade, em uma dinâmica que também considerou as suas variantes, ou seja, palavras ou expressões que, no contexto do documento analisado, tinham/ têm o mesmo significado segundo nossa interpretação. Assim, consideramos estes conceitos estruturantes para o Ensino Médio: interdisciplinaridade, contextualização, formação para ao trabalho e para a cidadania (formação humana integral), habilidades e competências.

A relevância das expressões citadas, candidatas a conceitos, pode ser também estimada pelo número de vezes que aparecem nos documentos analisados, o que pode ser visualizado no Gráfico 1.

Gráfico 1: Visualização da frequência com que aparecem os conceitos considerados estruturantes nos documentos oficiais do Ensino Médio

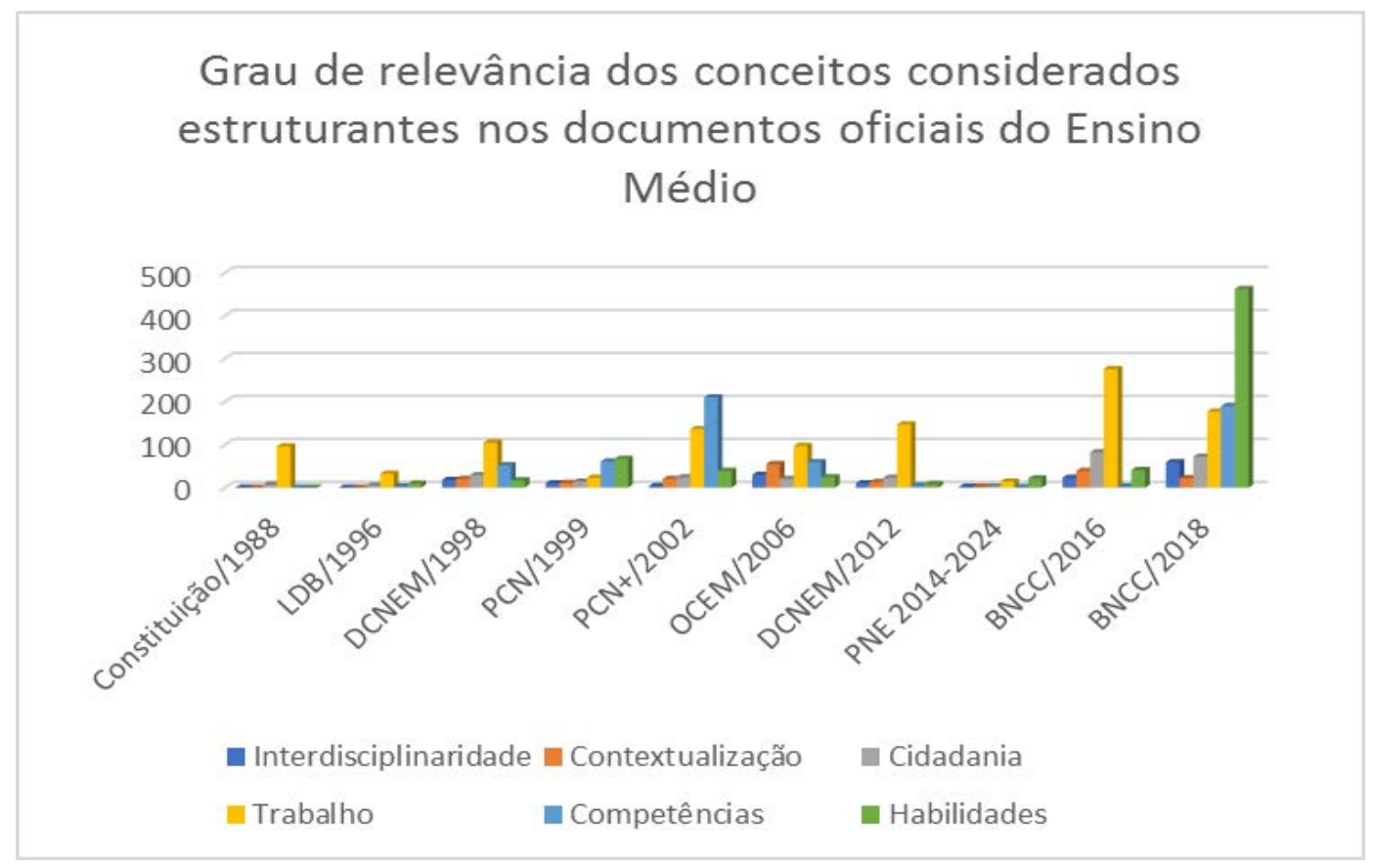

Fonte: a primeira autora.

Percebe-se que há uma repetitividade notável (crescente) do termo trabalho (formação para o trabalho); também aparecem muito competências, habilidades e contextualização, tomados como princípio e proposta pedagógica nos documentos.

Na linha metodológica de análise adotada na pesquisa (STRAUSS, 1987), retornamos aos textos para novas leituras, microanálise, questionamentos e atribuição 
de significados e apresentamos, a seguir, os conceitos atribuídos a partir dos documentos oficiais buscando levantar categorias.

$\mathrm{O}$ conceito de interdisciplinaridade foi identificado inicialmente nas DCNEM (BRASIL, 1998) e a discussão sobre esse tema estende-se por todos os documentos oficiais subsequentes, ainda que a repetitividade do termo não seja notável no Gráfico 1. A interdisciplinaridade, a partir dessa perspectiva, considera que todo conhecimento mantém um diálogo permanente com outros conhecimentos, seja de questionamento, confirmação, contemplação, negação ou ampliação. A interdisciplinaridade apresenta-se como uma prática pedagógica e didática, um princípio estruturador do currículo. A proposta da interdisciplinaridade é ir além da mera justaposição de conhecimentos, de disciplinas, com o cuidado de evitar a diluição em generalidades. A interdisciplinaridade é tomada como promotora de uma visão orgânica do conhecimento, pois alia os conteúdos de ensino a situações de aprendizagem amplas, produzindo um diálogo entre esses componentes (BRASIL, 1998, 2012, 2014, 2018).

Destacamos a relação estabelecida entre o currículo e a interdisciplinaridade: é por meio de uma visão orgânica do conhecimento, na qual conteúdos de ensino e situações de aprendizagem devem apresentar as múltiplas interações entre as disciplinas do currículo que se concretiza a interdisciplinaridade. Esse conceito é uma das propostas centrais das mudanças educacionais que a LDB (BRASIL, 1996), assim como os PCNs (BRASIL, 1999), PCN+ (BRASIL, 2002) e as OCEM (BRASIL, 2006) buscam promover, tentando estabelecer um diálogo com o professor e com o gestor escolar, discutindo exemplos e metodologias que propiciem as mudanças propostas pela legislação. Em especial, buscam atentar para a interdisciplinaridade e contextualização como articuladores do currículo desse novo Ensino Médio esperado. Para isso, apresentam exemplos de temáticas que envolvem um olhar articulado e abrangente, como o conceito de energia e o seu papel na Física, Química e Biologia. Destacam que a interdisciplinaridade, como uma visão de mundo, transcende a um conhecimento prático essencial da Educação Básica (BRASIL, 1999; 2002).

A contextualização também é apontada como um princípio estruturador do currículo. Ela é compreendida como uma estratégia articulada com a interdisciplinaridade e utilizada para relacionar o conhecimento escolar com o conhecimento cotidiano do estudante. A contextualização evoca áreas, âmbitos e dimensões presentes na vida pessoal, social e cultural do educando, promovendo um reconhecimento entre ele e o 
objeto de conhecimento, estabelecendo uma relação de reciprocidade e mobilizando competências já adquiridas, com o cuidado de que essa aproximação não conduza à banalização. $\mathrm{O}$ conhecimento comum precisa ser problematizado e superado. Dessa forma, contextualizar facilita a emergência do significado da experiência de aprendizagem escolar e a (re)significação da aprendizagem (BRASIL, 1998, 1999, 2002, 2012).

Os documentos também sugerem a contextualização histórica, na qual o conhecimento físico deve ser interpretado como uma construção histórica da humanidade, mas a ampliam abordando o conhecimento científico e tecnológico. Este último é tomado como algo que faz parte do mundo vivencial da sociedade moderna e como ele pode ser motivador e presumivelmente mais significativo para o aprendizado do estudante (BRASIL, 1999, 2002, 2006).

A formação para o trabalho e para a cidadania está fortemente ligada à interdisciplinaridade, à contextualização e à formação crítica. Essa noção é apresentada inicialmente pela LDB (BRASIL, 1996). Segundo a LDB, o vínculo com o mundo do trabalho e com a prática social e o exercício da cidadania fazem parte da formação em nível médio, potencializam a promoção e o aprimoramento do educando, seu desenvolvimento intelectual, seu pensamento crítico e sua compreensão dos fundamentos tecnológicos e científicos.

O conceito de formação para o trabalho e para a cidadania identificava a necessidade de um ensino com uma formação básica, voltado para o desenvolvimento da capacidade de aprender e compreender do mundo físico, social e cultural e previa uma parte diversificada para dar conta das peculiaridades locais e regionais (BRASIL, 1998, 2010, 2012). Dessa forma, assim como a interdisciplinaridade e a contextualização, a formação para o trabalho e a cidadania também estão relacionadas ao currículo - não como mera seleção e organização de saberes, mas enquanto formação de identidades (SILVA, 2000) - e trazem a noção de formação crítica, ao fazer referência explícita ao "pensamento crítico".

O conceito de competências surge na LDB (BRASIL, 1996), ao apresentar a organização da educação apontando para a necessidade do estabelecimento de competências gerais e diretrizes para a constituição de uma formação comum na Educação Básica. Essa colocação foi reforçada pelas DCNEM (BRASIL, 1998), que apresentavam explicitamente as competências e habilidades que deveriam ser estimuladas durante essa etapa educacional. 
Os documentos argumentam que a formação básica esperada é fundamentada na constituição de competências, habilidades e conduta em detrimento do acúmulo de informações. Dessa forma, o estudante deve ser estimulado a aprender a aprender, a pensar, relacionando o conhecimento escolar com os dados da experiência cotidiana, dando significado ao aprendido e captando o significado do mundo, relacionando teoria e prática, fundamentando a crítica e a argumentação com base em fatos. Esse aspecto tem importância crescente frente ao cenário cada vez mais preocupante de proliferação de fake news e de um estado de pós-verdade na atualidade.

Observamos que os conceitos estruturantes do Ensino Médio se relacionam por meio do currículo. Eles foram/são os próprios documentos legais que orientam uma reformulação curricular em que se priorizassem competências do tipo geral, em detrimento de um currículo enciclopédico; em que os conteúdos curriculares fossem ressignificados, adotando-se estratégias de ensino diversificadas (exercendo a interdisciplinaridade e a contextualização) que privilegiassem o raciocínio, se potencializassem a interação entre educando-professor e educando-educando e se propiciasse a negociação de significados (BRASIL, 1998, 1999, 2002) em uma dinâmica de construção coletiva.

Nesse novo currículo, o educando deveria ser estimulado a se reconstruir/reinventar e deveriam ser incentivados o seu protagonismo e sua autonomia intelectual.

Em suma, os conhecimentos deveriam ser tratados de forma interdisciplinar e contextualizada dando significado ao conhecimento aprendido. Especificamente, em relação à Física, destacava-se a necessidade de dar um novo sentido ao estudo da Física e do uso dos seus conhecimentos como instrumento de compreensão do mundo. Essa visão deixava de lado a preocupação com "o que ensinar de Física" e apontava para um novo horizonte, ou seja, "para que ensinar Física". Tal colocação pressupõe preparar o estudante para ser capaz de lidar com situações reais e/ou complexas, tais como: posicionar-se criticamente frente a crises de energia, questões socioambientais, poluição, aquecimento global, pandemias, movimentos anticientíficos (terraplanismo, movimento antivacina), pós-verdade, fake news, etc. (BRASIL, 2002).

É de notar que, após as Diretrizes de 1998 (BRASIL, 1998), não houve mais normativos até 2010 e que as Diretrizes Curriculares Gerais da Educação Básica de 2010 (BRASIL, 2010) silenciaram com respeito às competências e habilidades, ao 
passo que a interdisciplinaridade passou a fazer parte do currículo, sendo destinada $20 \%$ da carga horária da Educação Básica a projetos interdisciplinares.

A BNCC (BRASIL, 2018), por sua vez, retoma as competências alçando-as a fundamentos pedagógicos e afirma que a competência é uma marca na discussão pedagógica e social das últimas décadas, podendo ser inferida na LDB (Artigos 32 e 35) quando estabelece as finalidades gerais do Ensino Fundamental e do Ensino Médio.

A análise documental até aqui sumarizada aponta que os conceitos de interdisciplinaridade, contextualização, formação para o trabalho e para a cidadania (formação humana integral) e competências e habilidades são fortes candidatos a serem tomados como categorias, guiando a localização dos aspectos que marcam o "perfil esperado" do professor de Física para atuar no Ensino Médio em nosso País.

\section{Ensino Médio: a Física e a construção de um perfil do professor de Física, a partir dos documentos que regem o Ensino Médio}

Segundo a LDB (BRASIL, 1996), o currículo escolar é desenvolvido pela interação entre uma base nacional comum e o projeto pedagógico de cada escola, que deverá promover a formação para a cidadania e para o trabalho. Na citada lei, o currículo do Ensino Médio deve destacar a educação tecnológica básica, a compreensão do significado da ciência, os processos históricos e de transformação da sociedade e da cultura. Tal currículo deve ser implementado com metodologias de ensino que incentivem a participação ativa dos estudantes, incluindo os processos formativos de avaliação. Nessa perspectiva, a Física assume um novo caráter. A Física passa a ser entendida como uma cultura à qual o jovem tem direito e sua dimensão histórica e investigativa ganham relevância.

Assim, aprender Física, segundo a BNCC (BRASIL, 2016b, p. 147),

\footnotetext{
“(...) contribui para entender e posicionar-se criticamente frente a questões técnico-científicas da atualidade que envolvem diversos interesses e grupos sociais. A Física integra, desse modo, a cultura em seu sentido amplo, e deve ser tratada em contextos históricos, sociais que, ao lado de outros saberes, constituem um segundo eixo formativo para o aprendizado de Física.”

“(...) aprender física, trazendo a perspectiva investigativa para a vivência escolar, estimulando a crianças e jovens a formular hipóteses, enfrentar problemas abertos e contextualizados, em lugar de memorizar de fórmulas e aplicá-las a exercícios padronizados."
} 
Esse olhar para o ensino da Física (para a ciência, em geral) pretende que o professor seja capaz de apresentar uma Física que faça sentido ao estudante, preocupando-se com sua aprendizagem; promovendo discussões, intervenções e julgamentos práticos capazes de possibilitar ao estudante atuar ativa e conscientemente em sua comunidade. Também propõe promover a compreensão de procedimentos técnicos, a capacitação para realizar análises de informações, avaliação de riscos e benefícios em processos tecnológicos, atribuindo um significado amplo, tanto para uma atitude cidadã quanto para a compreensão das relações no mundo do trabalho.

Dessa forma, o educador deve ser um facilitador e encorajador da aprendizagem e, ao mesmo tempo, um inovador para pensar e colocar em prática um conjunto de estratégias diferenciadas e engajadoras.

O aprendizado do estudante deve, segundo a legislação examinada neste estudo, contribuir para a ampliação da cultura, para a interpretação de fatos e eventos naturais, para a descrição de procedimentos e equipamentos do cotidiano social e profissional e para a articulação de uma visão do mundo natural e social mais reflexiva. Enfim, espera-se que o educador promova um aprendizado de caráter prático e crítico (BRASIL, 1999).

O professor precisa ser um conhecedor profundo de saberes específicos (nesse caso, conhecer bem a Física) e de novas tecnologias para propiciar análises e avaliações que articulem ciência e tecnologia.

A partir desse novo olhar para a Física que se espera que possa ser ensinada no Ensino Médio, os documentos que regulam essa etapa da educação brasileira permitem traçar um perfil de educador alinhado com as propostas ali expressas e/ ou normatizadas, pois, se há expectativas para o processo de ensino-aprendizagem, isso requer (de forma implícita) que tenhamos professores com perfil adequado para executá-lo.

Dessa forma, o perfil do professor de Física esperado é o de um educador (enquanto profissional da Educação Básica) que tenha uma sólida formação inicial específica, em Física, e uma sólida formação pedagógica, no Ensino de Física; que seja capaz de aprender e aprender, dado que a ciência, a cultura e as próprias metodologias de ensino avançam constantemente e que formação continuada, enquanto um processo articulado de "mudança didática" e uma paulatina transformação do que pensa, crê e faz o professor (FURIÓ; CARNICER, 2002), é uma necessidade; que tenha uma ampla formação contextual e cultural, isto é, conheça a realidade escolar; que 
seja capaz de integrar teoria e prática pedagógica, dominando as novas tecnologias de comunicação e da informação articulando-as às suas práticas pedagógicas; que tenha capacidade para desenvolver um trabalho interdisciplinar e contextualizado, evidenciando em seus planejamentos a articulação, sempre que possível, com outras disciplinas de sua área e também com outras áreas do conhecimento.

Além disso, também se espera que seja capaz de propor estratégias de ensino diversificadas, como já dito, que privilegiem o raciocínio dos educandos e que potencializem as relações entre os agentes envolvidos (professor-educando, educando-educando, educando-comunidade, educando-gestores escolares). Nessa perspectiva, deve ter conhecimento de gestão escolar e de processos de avaliação que o habilitem a suplantar a avaliação tradicional, passando de uma avaliação quantitativa (baseada em provas) para uma avaliação formativa e processual que acompanhe 0 desenvolvimento dos educandos. A avaliação tradicional classifica e discrimina, ao passo que o acompanhamento individualizado consegue evidenciar progressos ou dificuldades (BRASIL, 1999; DANTAS, 2017).

Além desses aspectos e competências profissionais, também se espera do educador algumas competências psicológicas e de gerenciamento do próprio desenvolvimento profissional, tais como capacidade crítica, reflexiva e motivação, entre outras. O novo professor de Física deve ser capaz de assumir um papel de facilitador da aprendizagem, estimulando a realização de pesquisas, tarefas investigativas e de percepção da natureza da produção do conhecimento e o trabalho em grupo; de articulador de diferentes saberes escolares e a prática social, desenvolvendo nos educandos competências para o mundo do trabalho (BRASIL, 1996, 2002, 2012, 2017, 2018).

Para que isso se concretize, os documentos, em especial os PCN, PCN+ e OCEM, oferecem algumas sugestões: a abordagem Ciência, Tecnologia e Sociedade (CTS); a Aprendizagem Centrada em Eventos (ACE); a inserção da História e Filosofia da Ciência (HFC); o ensino de Física (de Ciências, em geral) por Investigação (EI). Essas abordagens apresentam-se como sugestões para operacionalizar um currículo interdisciplinar, abrangente e contextualizado, lembrando que currículo também é uma questão de construção de identidades (SILVA, 2000) no sentido de que ele sempre expressa escolhas, relações de poder e tensões sobre que tipo de identidade desejamos construir. 
Estamos de acordo que essas estratégias apresentam um grande potencial para o desenvolvimento da autonomia crítica e para propiciar ao estudante o contato com situações de aprendizagem que o levem ao exercício da tomada de decisões conscientes. Além disso, as abordagens aqui sumarizadas aproximam os estudantes à Física, apresentando-a como uma ciência viva que interage com o mundo ao seu redor; reafirmam a importância da experimentação no ensino de Física como forma de favorecer o desenvolvimento cognitivo e despertar o interesse em aprender conteúdos científicos (GOMES; BORGES; JUSTI, 2008), incentivando práticas experimentais que promovam a reflexão sobre a ciência (HODSON, 1994; BORGES, 2002), e incitem os educandos a fazerem mais perguntas do que dar as respostas, que aproximem, enfim, as dimensões teóricas da prática.

AFísica deve ser vista e ensinada como uma cultura capaz de formar um cidadão consciente e crítico do seu papel na sociedade contemporânea, instrumentalizado o jovem para compreender, intervir e participar da realidade (BRASIL, 2002). A Física escolar deve promover a compreensão dos fenômenos físicos, mostrando que esses fenômenos dialogam com o mundo a nossa volta, sejam eles naturais, sejam eles tecnológicos. Em outras palavras, deve ser ensinada e compartilhada como uma ciência que ajuda o estudante a agir no mundo contemporâneo (BRASIL, 2002). O estudo da Física deve levar o jovem a compreender significativamente os conceitos físicos para além da memorização e da habilidade no manuseio de fórmulas, alcançando o seu significado para sua vida e reconhecendo seu papel em uma aplicação tecnológica, por exemplo, sendo capaz de extrapolar o conceito inicial para explicar uma dada aplicação tecnológica (BRASIL, 2016b).

Assim, a partir da metodologia de análise utilizada nesta investigação, baseada na teoria fundamentada (com uso da microanálise, questionamentos, leitura/ releitura dos documentos, identificação de conceitos e codificação), fomos capazes de construir uma estrutura (Figura 1), que apresenta uma codificação axial, isto é, agrupa os conceitos estruturantes eleitos como categorias em torno de um eixo temático, que neste caso é o "perfil esperado" do professor de Física. O perfil esperado foi construído segundo nossa interpretação dos documentos oficiais das últimas três décadas que regulam o Ensino Médio no Brasil. 
Figura 1: Esquema do tipo "espinha de peixe" (STRAUSS; CORBIN, 2008) do Perfil Esperado para o Professor de Física, segundo os documentos públicos educacionais brasileiros das últimas décadas

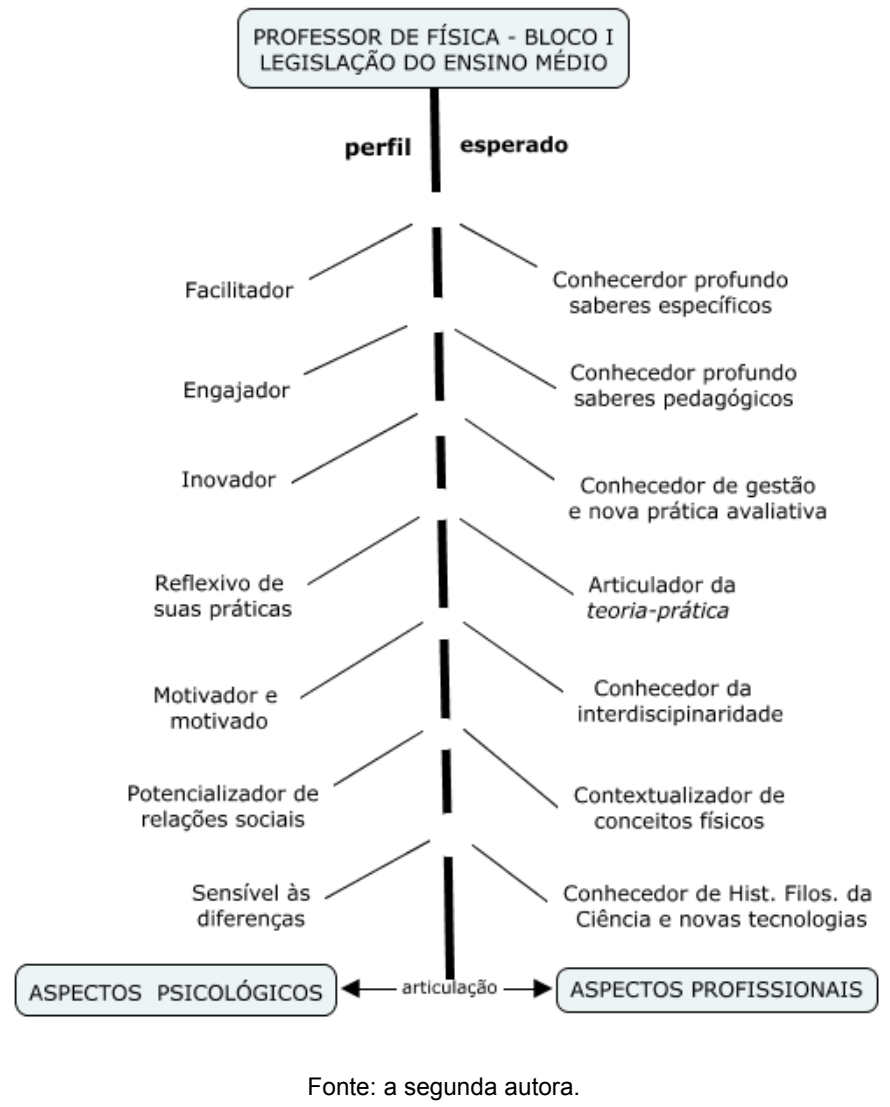

Destacamos o quanto esse perfil esperado é complexo. Exige do professor de Física, de um lado, um conjunto de conhecimentos, capacidades, percepções específicas e didáticas; de outro lado, um conjunto de habilidades individuais e psicológicas tais que se espera que ele seja capaz de abordar a Física como uma cultura, promovendo a criticidade, a interdisciplinaridade e a contextualização.

Diante da complexidade do perfil esperado, é possível inferir, na linha do discutido por Villani, Pacca e Freitas (2009), que as relações entre as políticas educacionais do Brasil e as demandas dos sistemas de ensino e da própria sociedade, frente a uma crescente desvalorização social da atividade docente, são tensas; que o desenho de propostas curriculares mais modernas evidenciado na análise das políticas públicas 
das últimas décadas, no fundo, espera que esse professor seja quase "sobre-humano" demonstrando que a construção desses normativos dificilmente o tomou como partícipe. Essa falta de participação dos próprios professores é uma das principais fraquezas desse processo, que, sem dúvida, representou avanços.

Assim, novamente colocamos alguns questionamentos: estariam os cursos de formação inicial suficientemente estruturados e aparelhados a ponto de conseguir oferecer esse perfil esperado? Se "idealmente" o professor de Física é formado com o perfil esperado, receberá, no exercício da docência, valorização e reconhecimento adequados? Poderíamos acrescentar à lista de questionamentos, frente ao que expõe o Parecer das Diretrizes Curriculares de 2015 (BRASIL, 2015), uma realidade nacional de baixíssimo percentual de professores de Física atuantes com formação na área: em que medida a atratividade para ser professor de Física pode ser ampliada diante dessa complexidade do "perfil esperado"?

\section{Ensino Superior: perfil pretendido para o egresso da Licenciatura em Física, segundo os documentos oficiais que regulam a Formação de Professores}

A legislação analisada nesta etapa constitui o que chamamos de Bloco 2 de documentos públicos, aqueles voltados à formação de professores, a saber: Constituição Federal (BRASIL, 1988); Lei de Diretrizes e Bases da Educação (BRASIL, 1996); Diretrizes Nacionais Curriculares para os Cursos de Física (BRASIL, 2001); Diretrizes Curriculares Nacionais para a Formação de Professores da Educação Básica (BRASIL, 2002); Diretrizes Curriculares Nacionais para a Formação Inicial e Continuada de Profissionais da Educação Básica (BRASIL, 2015) e Plano Nacional da Educação (BRASIL, 2014). Em dezembro de 2019, foram propostas novas Diretrizes Curriculares Nacionais para a Formação Inicial de Professores para a Educação Básica (BRASIL, 2019); no entanto, a análise desse documento não fez parte do escopo desta pesquisa.

Os dois documentos legais que regiam os cursos de formação de professores, Diretrizes Curriculares Nacionais para a Formação de Professores da Educação Básica (BRASIL, 2002) e Diretrizes Curriculares Nacionais para a Formação Inicial e Continuada de Profissionais da Educação Básica (BRASIL, 2015), propunham promover grandes reformas na formação docente, alinhadas aos documentos que normatizam 
o Ensino Básico, como afirmavam os próprios documentos, além de focalizarem na valorização desses cursos e dos profissionais que deles egressam. Destacamos que o Estudo 3 da tese de doutorado, investigação da qual este texto é parte, foi propositivo no sentido de sugerir e planejar uma disciplina interdepartamental para oportunizar aos futuros professores de Física (de Química e Biologia também) uma vivência interdisciplinar, tudo no âmbito das Diretrizes de 2015 (BRASIL, 2015). Assim, todo esse bloco de análise toma como dados os normativos que vão até as Diretrizes de 2015 (BRASIL, 2015) e não toca nas Diretrizes de 2019, que ainda são objeto de estudo no âmbito da Universidade que é contexto desta pesquisa.

Os documentos propunham, então, que a formação dos profissionais do magistério deveria ser entendida na perspectiva social e alçada ao nível de política pública, articulando formação inicial e continuada, tendo por eixo estruturante uma base nacional comum, posteriormente materializada na BNCC (BRASIL, 2018).

Os princípios fundamentais que nortearam a reformulação dos cursos de licenciatura foram, segundo o normativo: sólida formação teórica e interdisciplinar; unidade teoria-prática; trabalho coletivo e interdisciplinar; compromisso social e valorização do profissional da educação; gestão democrática; avaliação e regulação dos cursos de formação (BRASIL, 2015). Além disso, aparecia a docência como ação educativa e como processo pedagógico intencional e metódico, inter-relação de conhecimentos específicos, interdisciplinares e pedagógicos; conceitos, princípios e objetivos da formação que se desenvolvem na socialização e construção de conhecimentos, no diálogo constante entre diferentes visões de mundo.

Nessa linha, o currículo era entendido como um:
“(...) conjunto de valores propício à produção e à socialização de significados no espaço social e que contribui para a construção da identidade sociocultural do educando, dos direitos e deveres do cidadão, do respeito ao bem comum e à democracia, às práticas educativas formais e não formais e à orientação para o trabalho (BRASIL, 2015, p. 22)."

Seguindo os passos da teoria fundamentada como uma ferramenta de análise qualitativo-interpretativa, foi feito um escrutínio dos documentos oficiais brasileiros que orientam/orientaram a estruturação dos cursos de formação de docentes para Educação Básica no país. Por meio da microanálise, identificamos, como na etapa precedente, conceitos que atravessam os vários documentos oficiais e que nos levaram à elaboração do perfil pretendido do professor de Física segundo essa legislação. 
Consideramos como conceitos estruturantes para a formação do docente: sólida formação teórica e interdisciplinar; relação teoria-prática (vivência escolar distribuída na formação); interdisciplinaridade; contextualização; pesquisa.

No âmbito da microanálise, retornamos aos textos para identificar significados (tanto desses conceitos quanto de expressões correlatas) e apresentamos, na sequência, esses significados interpretados a partir dos documentos oficiais, buscando levantar categorias.

A abordagem encontrada de sólida formação teórico e interdisciplinar argumenta que a formação inicial deve oferecer ao licenciando conhecimentos básicos que garantam o domínio dos temas abordados na Base Nacional Comum Curricular - BNCC (BRASIL, 2015, 2018). O professor tem que conhecer o conteúdo específico que vai ensinar. Essa colocação pode parecer óbvia, mas, quando analisamos o Parecer que embasou as Diretrizes Curriculares Nacionais para a Formação Inicial e Continuada de Profissionais do Magistério da Educação Básica (BRASIL, 2015) sobre o perfil dos professores de Física atuantes no Brasil, à época, compreende-se sua importância. Esse documento dedica várias páginas ao estudo do "perfil da docência no Ensino Médio regular" e pontua a situação dos docentes de Física como: professor típico de Física leciona Física e outras disciplinas, geralmente, Matemática; de um universo de 50.543 docentes, apenas 13.565 (26,8\%) possuem formação específica, ou seja, $73,2 \%$ dos professores atuantes não tinham, até 2015, formação específica em Física (BRASIL, 2015, Parecer CNE/CP 2/15, p. 17). Não temos muitas razões para acreditar que a situação tenha mudado desde então.

Implementar uma sólida formação teórica e interdisciplinar é também repensar o currículo dos cursos de formação. Ao fazer esse movimento de repensar a formação, as Diretrizes incentivam a construção de uma identidade própria para o curso de Licenciatura. Implementar disciplinas voltadas exclusivamente para a formação de professores promove vivências importantes, como cuidar da transposição didática. Sem ela o processo de ensino-aprendizagem torna-se abstrato e dissocia teoria e prática. Licenciandos que não tiveram a oportunidade de vivenciar essas situações tendem a ter ainda mais dificuldade para enfrentar os desafios da educação científica do século XXI, pois serão eles que, no futuro, terão de selecionar conteúdos e promover a transposição didática que eles próprios não vivenciaram em sua formação (BRASIL, 2002, 2015).

Além disso, disciplinas específicas voltadas para os licenciandos (isto é, desvinculadas das amarras históricas com o bacharelado) também têm o potencial de promover uma relação clara entre o que o futuro professor está aprendendo e o que deverá ensinar no Ensino Médio, nível de ensino em que a maioria dos egressos de Física atua. Tais disci- 
plinas têm o potencial de amenizar as dificuldades que os estudantes enfrentam para correlacionar os conhecimentos específicos às práticas pedagógicas. Adicionalmente, criam um espaço para que os licenciandos interajam com os colegas, com os docentes formadores, com o contexto escolar e simulem/executem atividades de sala de aula (ROCHA, 2016a, 2016b; SALGADO, 2015; HEINDEMANN; GIONGO; MORAES, 2020).

A oportunidade de vivenciar diferentes espaços educativos e experienciar diferentes estratégias didáticas enriquece a formação do futuro professor (SALGADO, 2015). Segundo Carvalho e Gil-Pérez (2011), a vivência de propostas inovadoras e a reflexão didática, conectada diretamente com as práticas docentes, constituem o núcleo integrador dos diferentes saberes da formação docente, sendo requisitos básicos da didática das ciências como eixo articulador da formação de professores. A importância dessa mobilização já fora apontada por Bruner (1998) na década de 1960, embora seja importante destacar que o contexto de Bruner era o das escolas norte-americanas preocupadas com a formação de cientistas em plena Guerra Fria:

"Um currículo é mais para os professores do que para os alunos. Se não conseguir mudar, movimentar, perturbar e informar os professores, não terá efeito nos que vão aprender. Tem de ser essencialmente e em primeiro lugar um currículo para professores. Se exercer efeito sobre os alunos, será por tê-lo exercido sobre os professores (BRUNER, 1998, p. 15)”.

A relação entre o currículo cursado pelos licenciandos e o perfil do profissional egresso é direta (MARCHAN; NARDI, 2015), pois o currículo representa uma forma primária de materializar as relações de poder (SILVA, 2000). Se, como preconizam os documentos oficiais brasileiros, queremos formar um professor que implemente práticas interdisciplinares, contextualize adequadamente os temas de Física e utilize metodologias ativas e diferenciadas para promover uma aprendizagem com significado, crítica e voltada para a cidadania, o currículo formativo terá de proporcionar esses mesmos momentos.

Como Pinar (2014) chama a atenção, teorias do currículo estão envolvidas, implícita ou explicitamente, em desenvolver critérios de seleção que justifiquem a escolha do conjunto de conhecimentos para ser ensinado, mas não só envolvam questões de identidade, para que o professor não seja levado a cumprir prescrições acriticamente, afastando-o do modelo de racionalidade técnica e de proletarização do professor, como denunciam vários pensadores (CONTRERAS, 2012; SCHON, 1992). 
Assim, ao pensarmos na formação do professor, é importante considerar tanto o currículo que ele cursará quanto os conteúdos desenvolvidos, as práticas pedagógicas com as quais terão contato e até os ideais formativos dos docentes formadores (TAGLIATI; NARDI, 2015).

A relação teoria e prática é profundamente discutida nas diretrizes (BRASIL, 2002 , 2015). Sua perspectiva propõe mudanças profundas na formação docente, promovendo uma estreita, e mais equilibrada, relação entre esses temas. A discussão sobre a articulação entre teoria e prática é expandida nas Diretrizes Curriculares Nacionais para a Formação Inicial e Continuada de Profissionais da Educação Básica (BRASIL, 2015) que a coloca como facilitadora da integração, proporcionando significado e relevância aos conhecimentos e vivência da realidade social e cultural, além de contribuir ativamente para a construção do conhecimento.

O papel importante desse documento público (BRASIL, 2015) é o de reconhecer que essa articulação - teoria x prática - é fundamental para a formação. Além disso, requer que tal articulação tenha que ocorrer diluída em todo o curso, desde o primeiro ano, pois só assim o licenciando terá a oportunidade de conhecer a escola, vivenciar experiências que o transportem dos livros para a prática, lidando com imprevistos e mobilizando competências para lidar com eles. A diluição das experiências articuladas entre teoria e prática proporciona uma constante relação entre saber e saber fazer.

A interdisciplinaridade reaparece nesse Bloco de documentos públicos e é apontada como um eixo estruturador do currículo (BRASIL, 2002, 2015). Ela é interpretada como a articuladora entre conhecimentos específicos, vivências da realidade social e cultural e a preparação para o trabalho e o exercício da cidadania. Nas Diretrizes de 2015 (BRASIL, 2015), a importância da interdisciplinaridade é colocada com mais ênfase no texto, relacionando o trabalho docente a um trabalho coletivo e interdisciplinar e a uma sólida formação teórica e interdisciplinar.

O significado mais relevante que identificamos para esse conceito volta-se para a questão da articulação entre conhecimentos específicos e a realidade dos educandos. $\mathrm{O}$ documento coloca para o futuro professor a responsabilidade pela articulação, destacando que esse diálogo/articulação/questionamento do conhecimento deve ser vivenciado na sua formação inicial. Essa argumentação aproxima-se muito da visão de interdisciplinaridade de Ivani Fazenda (1992, 1994, 1991, 2001, 2002, 2003, 2006, 2010, 2014). Para a autora, a interdisciplinaridade é diálogo, questionamento e ação; é construída a partir do modo como cada ser humano vê o mundo, de suas 
vivências e envolvimento com estas. A interdisciplinaridade traz contida em si a proposição de ligação, conexão, diálogo. Ela busca promover trocas, intercâmbios, conexões e oportuniza vínculos. A interdisciplinaridade é construtora de pontes, é libertação de modelos pré-determinados, é mutação, questionamento e instiga o ato de constantemente nos revisitarmos.

Para a autora, do ponto de vista do ensino, interdisciplinaridade só tem sentido no encontro, na mutualidade, na relação de reciprocidade entre professor e estudante. Interdisciplinaridade é olhar para o ser humano como ser do mundo, é propor um novo olhar para a construção do conhecimento baseado na relação do ser humano com o mundo.

Interdisciplinaridade pressupõe expandir o olhar educacional para além das disciplinas, reconhecendo sua complexidade, inter-relações e interdependência (FAZENDA, 2003).

Japiassu (1976) endossa essa visão ao afirmar que a interdisciplinaridade é uma reação à especialização do conhecimento imposta pelo positivismo, um protesto contra a fragmentação do saber e o conformismo da reprodução de um conhecimento assumido como inquestionável. A interdisciplinaridade é assumida como uma atitude de permanente questionamento, propõe-se a explorar as fronteiras das disciplinas e as zonas intermediárias entre elas. Na universidade, a interdisciplinaridade busca adequar as atividades de ensino e pesquisa às necessidades socioprofissionais e superar o crescente distanciamento entre universidade e sociedade.

Esse novo olhar para o conhecimento proposto pela interdisciplinaridade precisa de um novo currículo para se concretizar. Assim, os princípios estruturantes da proposta de reforma curricular para a formação de professores estão entrelaçados: a sólida formação teórico interdisciplinar, a relação teoria-prática e a interdisciplinaridade são conceitos elevados a categorias que se apoiam mutuamente e vislumbram a sua efetivação por meio de uma reforma curricular.

Pensar em currículo é pensar o que se julga como conhecimento de maior valor para ser ensinado, como discutido na seção precedente. Essa análise revela que as teorias do currículo estão implicadas em desenvolver critérios de seleção que justifiquem a escolha do conjunto de conhecimentos para ser ensinado; trata-se de um trabalho que está relacionado, muitas vezes determinado, por temas políticos e educativos imbricados (SILVA, 2000). 
Para Tomaz Tadeu da Silva, essas escolhas e disputas de conhecimentos a serem ensinados andam lado a lado com a elaboração do perfil que se pretende construir com o currículo. Afinal, o currículo busca modificar as pessoas que vão segui-lo e carrega uma questão de identidade (SILVA, 2007), como comentado.

Segundo a perspectiva pós-estruturalista, o currículo é uma questão de poder e as teorias do currículo, à medida que buscam dizer o que o currículo deve ser, não podem deixar de estar envolvidas em questões de poder. Selecionar é uma operação de poder. Destacar, entre as múltiplas possibilidades, uma identidade ou subjetividade como sendo a ideal é uma operação de poder. As teorias do currículo estão ativamente envolvidas na atividade de garantir o consenso, de obter hegemonia. Elas estão situadas num campo epistemológico social; estão no centro de um território contestado, no qual teorias críticas e pós-críticas estão preocupadas com relações entre saber, identidade e poder (SILVA, 2000).

As teorias críticas, por sua vez, questionam os arranjos sociais e educacionais vigentes e preocupam-se em desenvolver conceitos que nos permitam compreender o papel do currículo. Teorias pós-crítica e crítica combinam-se, na tentativa de compreender os processos pelos quais, através das relações de poder e de controle, tornamo-nos naquilo que somos, pois ambas consideram o currículo como uma questão que envolve disputas, identidade e poder (SILVA, 2010).

Com base nas teorias críticas e pós-críticas do currículo, torna-se impossível pensar o currículo simplesmente através de conceitos técnicos como os de ensino e eficiência do ensino (perspectiva de Bruner (1998), como já dito) ou de categorias psicológicas como as de aprendizagem e desenvolvimento ou, ainda, de imagens estáticas como as de grades curriculares e lista de conteúdos.

As teorias críticas tomam o currículo como um espaço de disputa e poder, como uma construção social, resultado de um processo histórico. É apenas uma contingência social e histórica que faz com que o currículo seja dividido em matérias ou disciplinas, que se distribua sequencialmente em intervalos de tempo determinados, que esteja organizado hierarquicamente. O mesmo se pode dizer sobre os conhecimentos presentes no currículo, eles são parte de um processo de invenção social que escolhe certos conhecimentos e outros não (SILVA, 2000). Para o autor, teorias pós-críticas ampliam e modificam as teorias críticas; elas continuam a enfatizar que o currículo não pode ser compreendido sem uma análise das relações de poder nas quais ele está envolvido. No entanto, para as teorias pós-críticas, o poder está des- 
centrado; ele se transforma, mas não desaparece, e o conhecimento é parte inerente do poder. As teorias pós-críticas enfatizam, assim, o papel formativo do currículo.

O currículo é também autobiografia, a nossa vida, o curriculum vitae: o currículo forja a nossa identidade. O currículo é texto, discurso, documento. "O currículo é documento de identidade" (SILVA, 2000, p. 155).

É nesse viés que o currículo dos cursos de licenciatura precisa sem pensado, isto é, não é possível ignorar que a seleção de tópicos, disciplinas, carga horária, sequenciamento, tudo isso seja uma negociação de poder no interior dos grupos das instituições formadoras de professores, estejamos ou não conscientes disso.

A contextualização, assim como a interdisciplinaridade, é um dos princípios formativos apontado nas Diretrizes. Contextualizar, nesse contexto, significa olhar para o contexto escolar em que o professor atuará e reconhecer que nenhuma escola ou turma é igual a outra; pressupõe olhar para cada situação particular, analisar suas especificidades e, então, construir junto com aquela comunidade um significado para o conhecimento (BRASIL, 2002, 2015).

Destacamos a importância da contextualização dos conhecimentos como ponto fundamental para uma formação, inicial e continuada, e para a autonomia profissional docente. O docente que atuará no Ensino Básico tem esse desafio. Cada vez mais os saberes escolares são colocados em questão. As exigências da sociedade do século XXI fazem com que a pertinência do que se ensina e a formação que a escola oferece sejam continuamente questionadas. Nesse processo, o professor é/deve ser protagonista. Especialmente no ensino de Física, isso se torna evidente, pois, ao mesmo tempo que os alunos convivem com acontecimentos sociais significativos relacionados à ciência e à tecnologia, a escola mantém um currículo conservador e pouco relacionado com os debates científicos atuais (RICARDO, 2010), revelando a necessidade de atualização permanente, do educador e do currículo.

Assim como a interdisciplinaridade, a contextualização é um diálogo com o mundo. Esse diálogo não ocorre apenas entre saberes escolares e a realidade do educando, mas também entre professor e educando como agentes de uma construção coletiva. É uma tentativa de mediar os saberes escolares que se quer ensinar e, ao mesmo tempo, a possibilidade de ampliar o diálogo entre professor e estudante.

A contextualização tem na formação o potencial de possibilitar a construção de significados, evitando que o futuro docente seja apenas um mero transmissor de informação. As Diretrizes de 2002 (BRASIL, 2002) discutiam muito a formação inicial 
propedêutica contrapondo-a ao novo olhar proposto para a educação do século XXI, pois um professor com uma visão propedêutica da educação não se sustenta mais como professor na nova proposta educacional. Essa colocação reforça a importância da reformulação curricular sugerida no documento.

No entanto, para que contextualização e interdisciplinaridade tenham realmente impacto nas salas de aula do Ensino Básico, é necessário que estejam presentes na formação, que sejam vivenciadas pelos futuros professores porque só quando o professor é realmente mobilizado pelo currículo é que teremos mudanças na sua prática (BRUNER, 1998).

A pesquisa é um dos pivôs na formação docente, pois tem potencial para promover reflexão sobre suas práticas e alcançar autonomia profissional pelo constante questionamento sobre seu próprio processo de ensino e de aprendizagem (BRASIL, 2002, 2015). Para Paulo Freire, ensinar exige consciência do inacabamento. "Como professor crítico, sou um 'aventureiro' responsável, predisposto à mudança, à aceitação do diferente. Nada do que experimentei em minha atividade docente deve necessariamente repetir-se". (FREIRE, 1996, p. 50).

O sentido de transformação mencionado por Freire pode ser levado à sala de aula pela integração de resultados de pesquisa. Os conhecimentos produzidos pela investigação acadêmica nas diferentes áreas, especialmente a que compõe sua formação, alimentam o desenvolvimento profissional, possibilitam ao professor manter-se atualizado e fazer opções em relação aos conteúdos, à metodologia e à organização didática dos conteúdos. A pesquisa também apresenta o potencial para proporcionar autonomia ao futuro docente, não só como participante da iniciação científica, mas também como docente que conhece a análise, o desenvolvimento e a aplicação dos resultados de investigações de interesse da sua área de atuação, sendo capaz de mobilizar conhecimentos para implementá-los na sua prática pedagógica (BRASIL, 2002, 2015).

Esse aspecto, contudo, é colocado pelos documentos públicos como um desafio a ser superado, uma vez que reconhecem que há avanços em termos da Pesquisa em Ensino de Ciências (de Física) e na área de Formação de Professores, mas que os resultados desta pouco/senão quase nada chegam à sala de aula da Educação Básica.

De forma idêntica ao procedido na seção anterior, a nossa metodologia de análise fez uso da microanálise, da sistemática de questionamentos, da leitura/releitura dos documentos públicos deste Bloco 2, isto é, documentos públicos que regem a formação de professores no Ensino Superior, para identificar conceitos estruturantes. A partir 
da nossa interpretação dos seus significados, construímos a Figura 2, que apresenta uma codificação axial, agrupando vários aspectos que se mostraram relevantes em torno de um eixo que chamamos "perfil pretendido" do professor de Física.

Figura 2: Esquema do tipo "espinha de peixe" (STRAUSS; CORBIN, 2008) do Perfil Pretendido para o professor de Física, segundo os documentos públicos educacionais brasileiros que regem a formação de professores das últimas décadas

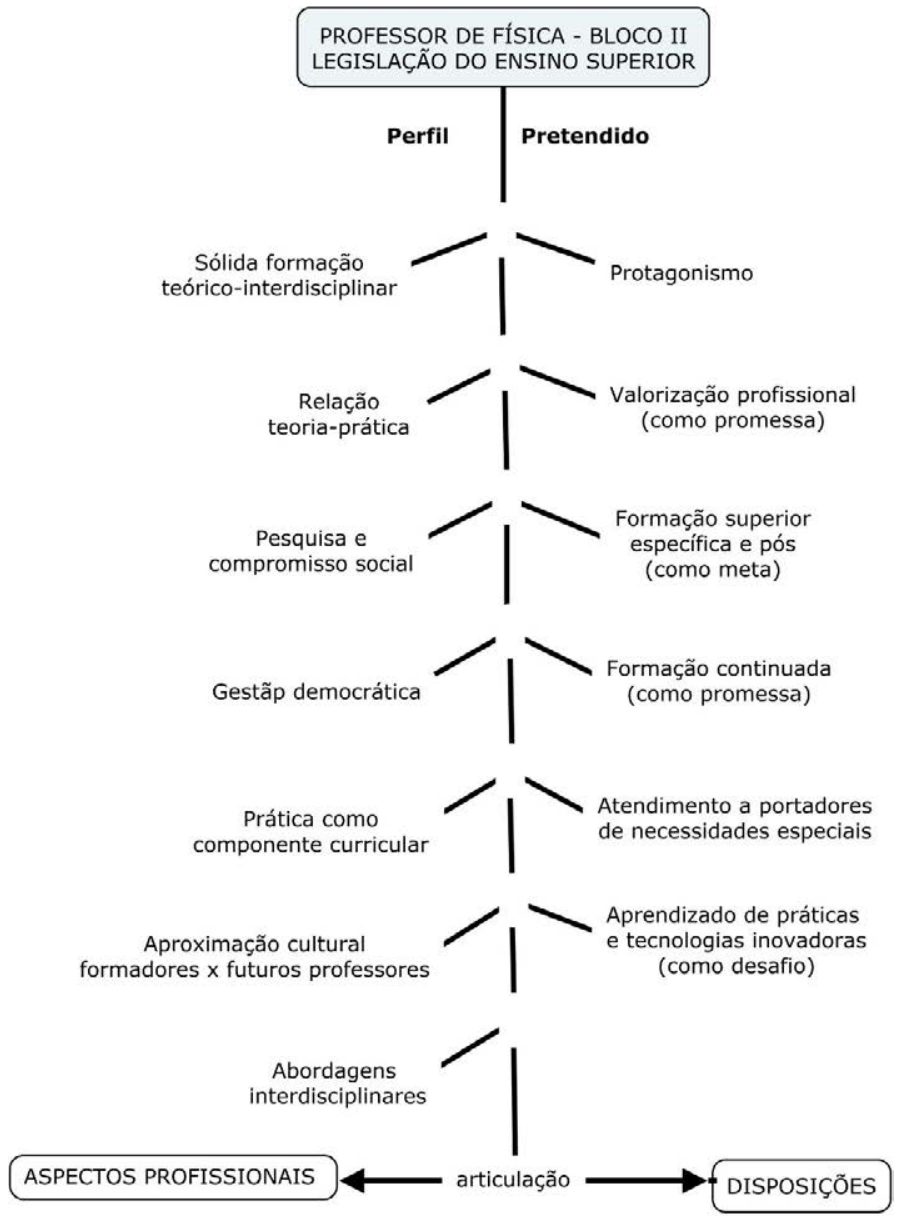

Fonte: a segunda autora.

A estrutura da Figura 2 ajuda a perceber que o perfil pretendido para o professor de Física nas legislações recentes sobre formação de professores (BRASIL, 1996, 2002, 2015) é complexo, assim como se revelou o perfil esperado, comentado na seção anterior. O professor é/deve ser protagonista da ação educativa, autônomo 
e conhecedor da comunidade em que leciona. Porém, além dos saberes específicos, pedagógicos e interdisciplinares, deve ter conhecimentos de gestão educacional e habilidades para o trabalho em equipe e expertise para relacionar teoria e prática.

Através de disciplinas específicas, pedagógicas e de vivências práticas, quer nos estágios supervisionados (400 horas), quer nas práticas como componente curricular obrigatório e distribuídas ao longo da formação inicial (400 h), a legislação pretende que seja possível que os futuros professores consigam construir um perfil de facilitador e motivador do conhecimento; de agente reflexivo de suas práticas, capaz de promover o compartilhamento dos saberes da Física por meio de metodologias inovadoras e estratégias engajadoras que gerem compreensão de conceitos e também reflexão crítica nos educandos.

\section{Considerações finais}

A título de síntese, a Figura 3 busca articular os dois perfis: o perfil esperado (identificado no Bloco 1) e o perfil pretendido (identificado no Bloco 2).

Figura 3: Busca articular perfil esperado discutido nos documentos do Bloco 1 e o perfil pretendido do professor de Física, que emergiu do Bloco 2. As cores indicam conceitos interligados nas duas estruturas

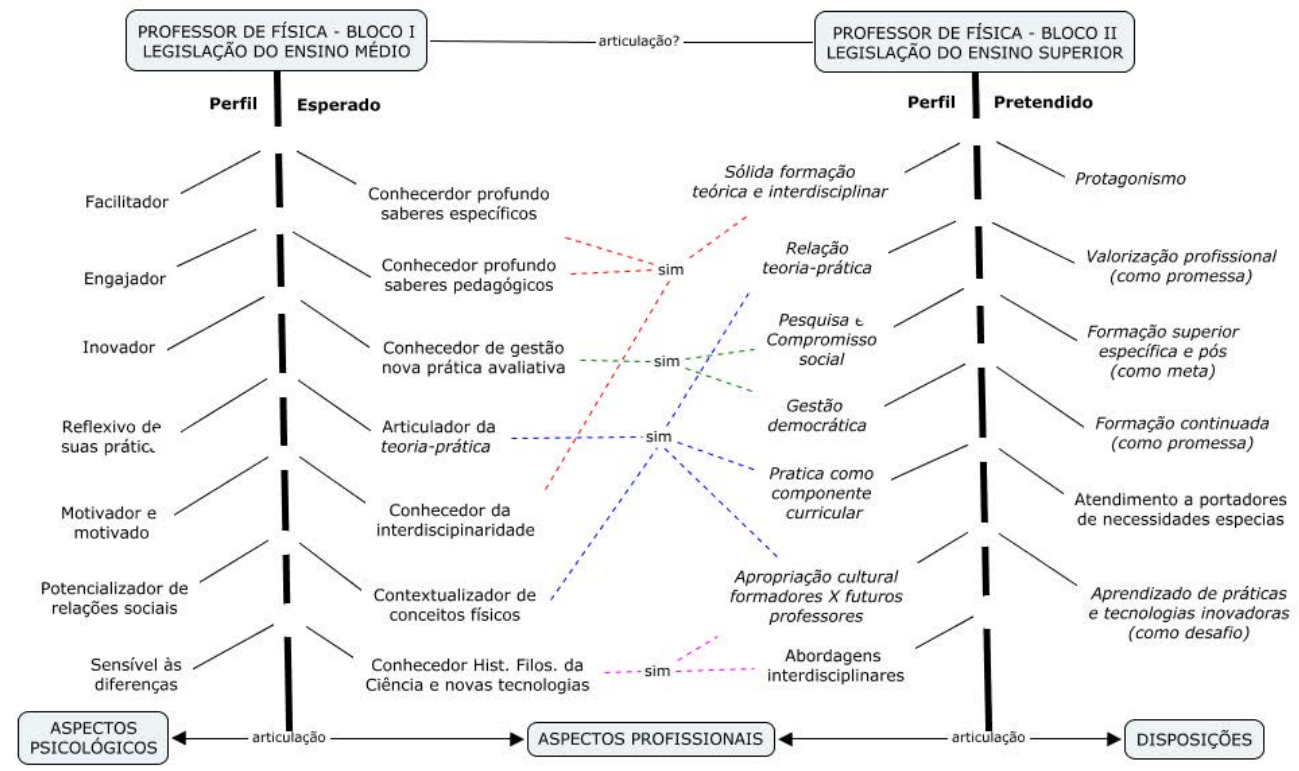

Fonte: a segunda autora. 
A comparação dos perfis mostra que as legislações recentes que regulam a formação de professores (Bloco 2, nesta análise) estão alinhadas, em boa medida, àquelas que normatizam o Ensino Médio (Bloco 1) no que diz respeito à sólida formação específica, pedagógica e interdisciplinar, à adoção da interdisciplinaridade, contextualização e de um currículo voltado para a formação cidadã. Isso pode ser visto através das linhas tracejadas de distintas cores que interligam grupos de conceitos nas duas estruturas da Figura 3. Tal currículo no Ensino Médio precisa ser construído em discussões com seus pares, com os educandos e com a comunidade escolar e sustentado por pesquisas na área de Ensino de Ciências e outras áreas afins. Daí o papel do protagonismo e da pesquisa, tanto na formação inicial e continuada quanto na educação científica que esse professor promoverá.

A Física é apresentada como uma cultura à qual todos os brasileiros tem direito, como uma construção humana inacabada, provisória e contextualizada à sociedade e que precisa ser também ensinada dessa forma, ou seja, contextualizada à realidade do estudante, daí a necessidade de que esse professor se aproprie de conhecimentos históricos, epistemológicos, levando em conta também necessidades especiais, diversidade cultural, de gênero, de etnias.

Em síntese, a análise minuciosa indicou que as legislações educacionais brasileiras (tanto a que regulamenta o Ensino Médio quanto a que regula os cursos de formação de professores no Ensino Superior) são avançadas e têm, nas últimas décadas, complexificado e maximizado os requisitos e o perfil do professor de Física para o nível médio, ao passo que políticas de valorização e reconhecimento desses profissionais têm ficado no campo da promessa, do desafio, da minimização.

Todos os aspectos mostrados na Figura 3 complexificam tanto o "perfil esperado" quanto o "perfil pretendido" para os professores de Física e, como já comentado, tomam esse docente como um quase "sobre-humano", o que coloca a pergunta: como aumentar a atratividade para a carreira docente diante de um perfil tão exigente e de uma realidade de desvalorização social de carreira e dos baixos salários? Isso nos coloca diante de desafios tão grandes que possivelmente demandem mobilização, participação e união de vários setores da sociedade e da comunidade acadêmica para (re)pensar a formação docente de forma mais articulada. 


\section{Creating a profile for the Basic Education Physics teacher: what does Brazilian legislation advocate?}

\section{Abstract}

This text is part of a broader research that, within the scope of a doctoral thesis, aims to reflect the initial training of Physics teachers in Brazil. This article discusses the profile of the Physics educator based on an analysis of the legal documents that rule High School and Higher Education. The elaboration of this profile was divided into two stages: the first presents the profile of the Physics teacher expected by the legal documents that rule High School, which is the largest area of activity for the graduate in Physics; and the second shows the intended profile of the Physics graduate from the documents that guide the Training of Teachers in Higher Education. With the constitution of this profile, we promote its articulation with theoretical references and with the literature on teaching knowledge and, thus, we think of more propositional investigations in the thesis. However, we understand that showing these profiles can contribute to the current debate on teacher training in our country, especially given the complexity of knowledge, skills, abilities, values and actions that are expected from such educator, according to official documents.

Keywords: Profile of the Physics teacher. Initial education. Public policies.

\section{Referências}

BORGES, T. Novos rumos para o laboratório escolar de Ciências. Caderno Brasileiro de Ensino de Física, v. 19, n. 3, p. 291-313, 2002.

BRASIL. Lei n. 5.692, de 11 de agosto de 1971. Estabelece as Diretrizes e Bases da Educação Nacional. Diário Oficial [da República Federativa do Brasil], Brasília, DF, 13 ago. 1971.

Constituição da República Federativa do Brasil, 1988. Disponível em: <http://www. planalto.gov.br/ccivil_03/Constituicao/Constituicao.htm>. Acesso em: 10 maio 2016.

Lei n. 9.394, de 20 de dezembro de 1996. Estabelece as Diretrizes e Bases da Educação Nacional. Diário Oficial [da República Federativa do Brasil], Brasília, DF, v. 134, n. 248, 23 dez. 1996.

Resolução CNE/CEB n. 3/1998, de 01 de junho de 1998. Estabelece as Diretrizes Curriculares Nacionais para o Ensino Médio. Diário Oficial [da República Federativa do Brasil], Brasília, DF, n. 120, 26 jun. 1998.

Parâmetros Curriculares Nacionais: Ciências da Natureza, Matemática e suas Tecnologias. Brasília, DF: Ministério da Educação, 1999.

Diretrizes Nacionais Curriculares para os Cursos de Física, 2001. Disponível em: <http://portal.mec.gov.br/cne/arquivos/pdf/CES1304.pdf>. Acesso em: 20 mar. 2020.

Orientações Educacionais Complementares aos Parâmetros Curriculares Nacionais PCN+ - Ensino Médio - Ciências da Natureza, Matemática e suas Tecnologias. Brasília, DF: Ministério da Educação, 2002. 
. Orientações Curriculares Para o Ensino Médio - Ciências da Natureza, Matemática e suas Tecnologias. Brasília, DF: Ministério da Educação, Secretaria da Educação Básica, 2006.

Resolução CNE/CEB n. 4/2010, de 13 de julho de 2010. Estabelece as Diretrizes Curriculares Gerais para a Educação Básica. Diário Oficial [da República Federativa do Brasil], Brasília, DF, n. 130, 9 jul. 2010.

Resolução CNE/CEB n. 2/2011, de 4 de maio de 2011. Estabelece Diretrizes Curriculares Nacionais para o Ensino Médio. Diário Oficial [da República Federativa do Brasil], Brasília, DF, n. 17, 24 jan. 2012.

. Lei n. 13.005, de 25 de junho de 2014. Estabelece o Plano Nacional de Educação. Diário Oficial [da República Federativa do Brasil], Brasília, DF, n. 120-A, 26 jun. 2014.

. Resolução CNE 02/2015, de 1 de julho de 2015. Estabelece as Diretrizes Curriculares Nacionais para a Formação Inicial e Continuada dos Profissionais do Magistério da Educação Básica. Diário Oficial [da República Federativa do Brasil], Brasília, DF, n. 124, 2 jul. 2015.

Base Nacional Comum Curricular (Segunda Versão Revista), 2016b. Disponível em: <http://basenacionalcomum.mec.gov.br/documentos/bncc-2versao.revista.pdf>. Acesso em: 17 maio 2016.

Conselho Nacional da Educação/Conselho Pleno. Resolução n. 4, de 17 de dezembro de 2018. Institui a Base Nacional Comum Curricular na Etapa do Ensino Médio (BNCC-EM), como etapa final da Educação Básica, nos termos do artigo 35 da LDB, completando o conjunto constituído pela BNCC da Educação Infantil e do Ensino Fundamental, com base na Resolução $\mathrm{CNE} / \mathrm{CP}^{\circ}$ - 2/2017, fundamentada no Parecer CNE/CP no 15/2017. Disponível em: http://portal.mec. gov.br/index.php?option=com_docman\&view=download\&alias=104101-rcp004-18\&Itemid=30192. Acesso em: 20 mar. 2020.

Diretrizes Curriculares Nacionais para a Formação Inicial de Professores para a Educação Básica, 2019. Disponível em: <http://portal.mec.gov.br/index.php?option=com_docman\&view=download\&alias=135951-rcp002-19\&category_slug=dezembro-2019-pdf\&Itemid=30192>. Acesso em: 20 mar. 2020.

BRUNER, J. O Processo da Educação. Lisboa: Edições 70, 1998.

CARVAlHO, A. M. P.; GIL-PÉREZ, D. Formação de professores de Ciências: tendências e inovações. 10 ed. São Paulo: Cortez, 2011.

CONTERAS, J. A autonomia de professores. São Paulo: Cortez, 2012.

DANTAS, C. R. S. Avaliação no ensino de ciências no Nível Fundamental: investigando orientações oficiais e práticas docentes, fazendo "escuta" e intervenções em escolas. 2017. Tese (Doutorado em Física) - Programa de Pós-Graduação em Ensino de Física, Universidade Federal do Rio Grande do Sul, Porto Alegre, 2017.

FAZENDA, I. Integração e interdisciplinaridade no ensino brasileiro: efetividade ou ideologia? São Paulo: Edições Loyola, 1992.

. Práticas interdisciplinares na escola. São Paulo: Cortez, 1994.

Dicionário em construção: Interdisciplinaridade. São Paulo: Cortez, 2001.

. Interdisciplinaridade: história, teoria e pesquisa. Campinas: Papirus, 2002. 
Interdisciplinaridade: qual o sentido? São Paulo: Paulus, 2003.

Interdisciplinaridade na formação de professores: da teoria à prática. Canoas: Ed. da Ulbra, 2006.

Metodologia de pesquisa educacional. São Paulo: Cortez, 2010.

Interdisciplinaridade: pensar, pesquisar e intervir. São Paulo: Cortez, 2014.

FREIRE, P. Pedagogia da autonomia: saberes necessários à prática educativa. São Paulo: Paz e Terra, 1996.

FURIÓ, C.; CARNICER, J. El desarrollo profesional del profesor de ciencias mediante tutorías de grupos cooperativos. Estudio de ocho casos. Enseñanza de las ciencias: Revista de Investigación y Experiencias Didácticas, v. 20, n. 1, p. 47-73, 2002.

GOMES, A. D. T.; BORGES, A. T.; JUSTI, R. Processos e conhecimentos envolvidos na realização de atividades práticas: revisão da literatura e implicações para a pesquisa. Investigações em Ensino de Ciências - IENCI, v. 13, n. 2, p. 187-207, 2008.

HEINDEMANN, L. A.; GIONGO, S. L.; MORAES, K. R de M. Evadir ou persistir? Uma disciplina introdutória centrada no fomento à persistência nos cursos de licenciatura em Física. Revista Brasileira de Ensino de Ciências e Matemática, v. 3, n. 1, p. 160-188, 2020.

HODSON, D. Hacia un enfoque, más crítico del trabajo de laboratorio. Enseñanza de las ciencias: Revista de Investigación y Experiencias Didácticas, v. 12, n. 3, p. 299-313, 1994.

JAPIASSU, H. Interdisciplinaridade e patologia do saber. Rio de Janeiro: Imago, 1976.

MARCHAN, G. S.; NARDI, R. Projetos pedagógicos de cursos: as vozes que emanam do processo de reestruturação dos cursos de licenciatura em Física de uma universidade pública. In:

Formação inicial de professores de Física em universidades públicas: estudos realizados a partir de reestruturações curriculares. São Paulo: Livraria da Física, 2015. Cap. 5, p. 133-152.

PINAR, W. F. La teoria del curriculum: estúdio introductorio. Madrid: Narcea, S.A. de Ediciones, 2014.

RICARDO, E. C. Problematização e contextualização no ensino de Física. In: CARVALHO, A. M. P. et al. Ensino de Física. São Paulo: Cengage Learning, 2010.

ROCHA, J. F. M. História de uma experiência singular de ensino. Parte I: a criação do Curso de Física, Licenciatura, noturno, da UFBA. Caderno Brasileiro de Ensino de Física, v. 33, n. 1, p. 253-274, 2016a.

ROCHA, J. F. M. História de uma experiência singular de ensino. Parte II: o caso das disciplinas "Físicas Básicas", da UFBA. Caderno Brasileiro de Ensino de Física, v. 33, n. 2, p. 527-555, 2016b.

SALGADO, T. D. M. Radioquímica: uma disciplina articuladora de conhecimentos pedagógicos e conhecimentos específicos na licenciatura em química. Textos FCC, v. 47, p. 1-108, 2015.

SCHÖN, D. La formación de professores reflexivos. Hacia um nuevo diseño de la ensenãnza y el aprendizage em las profesiones. Barcelona: Paidós/MEC, 1992.

SILVA, T. T. da. Teorias do currículo: uma introdução crítica. Porto: Porto Editora, 2000.

Documentos de identidade: uma introdução às teorias do currículo. Belo Horizonte: Autêntica, 2007. 
O currículo como fetiche: a poética e a política do texto curricular. Belo Horizonte: Autêntica, 2010.

STRAUSS, Anselm L. Qualitative Analysis for Social Scientists. Cambridge: Cambridge University Press, 1987.

STRAUSS, A. L.; CORBIN, J. Pesquisa Qualitativa: técnicas e procedimentos para o desenvolvimento de Teoria Fundamentada. 2. ed. Porto Alegre: Artmed, 2008.

TAGLIATI, J. R.; NARDI, R. Configurações curriculares e potenciais formativos de cursos de licenciatura em Física do estado de Minas Gerais. In: Formação inicial de professores de Física em universidades públicas: estudos realizados a partir de reestruturações curriculares. São Paulo: Livraria da Física, 2015. Cap. 7, p. 177-200. 